\title{
EPA Guidance on the Role and Responsibilities of Psychiatrists
}

Dinesh Bhugra CBE *

Professor of Mental Health and Cultural Diversity, Institute of Psychiatry (King's College London),PO25,HSPRD,DeCrespigny Park London SE5 8AF

Dr Martina Rojnic Kuzman, Department of Psychiatry, Zagreb University Hospital Centre, Zagreb Croatia

Professor George Ikkos, Consultant,St Ann's Hospital,London UK

Dr Marc H M Hermans, Kinder-en Jeugdpsychiater,Mechelen, 9100,Sint-NIklaas, Belgium

Dr Julian Beezhold, Hellesdon Hospital,Norwich (UK)

Professor Peter Falkai, University of Munich,Germany

Dr Andrea Fiorillo, Department of Psychiatry,University of Naples, Italy

Dr Alex Till, FY Trainee, University Hospitals of Leicester,Leicster,UK

Professor Micahel Musalek,

Dr Jolyon Dales,FY2 Trainee,University of Leicester,Leicester.UK

Professor Cyril Hoschl,

Dr Wulf Rossler

Dr Goran Racetovic, Centar za Mentalino Zdravlje,Prijedor,Bosnia and Herzegovina

Prof. Dr. Wolfgang Gaebel, Department of Psychiatry and Psychotherapy, Heinrich-Heine-University

Düsseldorf, Germany 
- For correspondence

\section{Abstract}

Psychiatry is a medical speciality dealing with mental illness, emotional and behavioural disturbances. A psychiatrist is a trained doctor who has received further training in the field of diagnosing and managing mental illnesses. The role of the psychiatrist is to deliver high quality psychiatric services and lead on service planning, development and delivery working with other team members.

Like many other organisations within the medical profession, the European Psychiatric Association seeks to rise to the challenge of articulating a definition that is fit for purpose in the 21st century as 
we work to deliver high-quality care for patients - in this case, the roles of psychiatrist in mental health services.

This paper seeks to map the roles that a psychiatrist carries in their professional capacity and to define the values and competencies which will aid us in delivering the best care for our patients - care that is clinically effective, safe and patient-centred.

This paper is directed toward psyciatrists, the medical profession as a whole, to other members of the multidisciplinary team in psychiatry to employers and commissioners, to educational and health service policy makers and patients and their carers.

Key Words: Psychiatrist, roles, responsibilities, competencies 


\section{Introduction}

Until the $19^{\text {th }}$ century those dealing with mental illness were known as alienists. Mental illness has been described for centuries across the globe and establishment of mental asylums has also been well noted in different countries and settings. Psychiatry emerged as a medical specialty and remains one in spite of many attempts to turn the subject into a matter of social concern and coercion and the antipsychiatry movement has taken root even among doctors and psychiatrists. It is essential to understand the concepts of mental illness and notions of mental health in general even though there will 
be differences across cultures and countries so that the role of the psychiatrist can be understood better.

In an elegant essay Hoschl and Libiger(10) argue that the authority of psychiatry as medical discipline depends upon the authority of medicine itself. They argue that were the authority of the discipline to be obscured the discipline will be blamed. Psychiatry can define and describe mental illness but it cannot explain undesirable social phenomena.

The last few decades have brought tremendous rapid changes in society, greatly influencing its various aspects including health, communication, ethics, politics and economics. These changes are related to globalisation, economic and demographic changes and the rapid rise of social media. Psychiatry, as a significant component of the healthcare system, has also been affected by these changes. Some of this change is reflected in modern psychiatric nomenclature - from a 'doctor' to a 'professional', a 'psychiatrist' to a 'mental health specialist', a 'patient' to a 'client' to 'user' or in some circumstances even a 'customer', and a 'community psychiatric nurse' to a 'care coordinator', a 'case manager' or a practitioner. We 
do not propose to go into pros and cons of such definitions but want to highlight the change that is still happening.

The role and responsibilities of psychiatrists may change as a result of changes in the society and under social pressures but the core responsibilities of diagnosis and management remain.

In a classic volume Hunter and Macalpine (11) highlight the development of the subject from 1535 although other accounts from earlier times in other healthcare systems also exist $(1,4)$. The discipline and practice of present day psychiatry deals not only with mental illness but behavioural and emotional disorders as well. Psychiatric practice often utilises bio-psychosocial approaches in understanding aetiological factors as well as management. Often psychiatrists are accused of following the 'medical model' too closely (24) and the critics ignore the fact that medicine itself is a social discipline. Indeed the term 'medical model' is used as a pejorative term to suggest that psychiatrists are not holistic in their 
approach but only concerned with formal diagnosis and medication.

Any number of social factors such as diet, religious views and attitudes to alcohol and smoking can affect how drugs are absorbed and act. Societal influences determine what is seen as deviant or sick and this may be more influential in psychiatry than in other medical disciplines. Social understanding of illness contributes to how symptoms are identified and what idioms of distress are used.

Like all doctors, psychiatrists also deal with a wide range of conditions varying from childhood disorders such as conduct disorders and nocturnal bed wetting to dementia at the other end of age spectrum as well as co-morbidities such as addictions and severe mental illness; physical and mental illness and personality disorders and mental illness. They also provide assessments and management in a number of conditions from sexual problems to common mental disorders such as depression and anxiety to learning disability in children or adults and personality disorders. Depending upon availability of resources, psychiatrists may themselves offer many intervention techniques or supervise and support others in delivery 
of such interventions. These strategies include not only medical care but aspects of social care, psychological interventions with or without medical treatments and in the process aim to empower some of the most vulnerable and marginalised people in society.

Mental health is defined as the absence of disease, as a state of the organism which allows the full performance of all its functions or as a state of balance within oneself and between oneself and one's physical and social environment $(3,23,24)$. Mental well-being and mental illness can be seen as opposite ends of the spectrum or in a continuum. In Maslow's hierarchy, mental and physical healths are related to how basic needs such as food, shelter, social functioning etc are satisfied but meta-needs such as beauty, goodness, justice and wholeness as essential for personal growth and fulfilment (17). Mental health is also an enabler for the individual in forming and maintaining effective and affectionate relationships and attachments which help the individual to lead a fulfilled life. Mental health 
demotion (as used by HEA but menaing deterioration) or increasing mental vulnerabilities can result from both the internal personal factors such as low self-esteem, sense of entrapment, helplessness and sadness and also external social and economic factors such as poor housing, poverty, and unemployment, discrimination or abuse, cultural conflict, stigma etc (9). A major challenge for psychiatry in the West has been mind-body dualism which has led to a split between not only physical and mental health but also in provision of such care.

Mental health is also about how individuals think and feel about themselves and their life, and its effect on their coping with adversity (18). Mental health is a state of equipoise and balance; where the individuals are at peace with themselves, able to function effectively socially, and look after their own basic needs as well as higher function needs (3). Positive functioning means managing change, managing relationships and managing emotions in a constructive manner. From an Indian perspective a model of mental health has been created (25) which introduces the concept of manas with 
three clinical criteria-awareness of the self, ability to relate well with others and all of one's actions are useful(or at least not harmful) to the self. On the other hand, mental illness is used to describe a variety of behaviour patterns which affect the smooth functioning of life. It is arguably a catch-all for a largely medical model for pathology arising from biological vulnerabilities, social maladjustments and psychological disturbances thus creating a biopsychosocial model of aetiology and management (12). Often mental illness and mental disorders are confused with each other though sometimes disorders refer to mental illness related to offending especially when individuals get into trouble with the law. These mental disturbances depend upon definitions of abnormality on the basis of statistical, physiological, psychoanalytic, behavioural or humanistic paradigms (13). Thus, what is abnormal and how this is defined is at the root of tensions between the professionals and society.

The capacity of mental health interventions to improve mental state and even physical health is often underestimated by the 
general public and other professionals even though recent evidence shows that anti-psychotic medication has comparative efficacy with those medication sin general medicine (!4). Mental health services are an essential feature of any contemporary civilised society, and yet are still too often stigmatised and neglected in terms of resources and support. Internalised stigma on part of professionals and external stigma by the society, policy makers and others has a major impact on patients, their families and carers.

In the past two decades phrases such as mental health issues or mental health problems (at least in the UK) are being used increasingly giving an impression that these disorders carry with them a lower degree of distress, difficulty and functional impairment. This usage and approach may make it appear that these conditions although common are not serious or that they even lack any underlying pathophysiological cause. This devalues, minimises and underestimates the gravity and degree of disability caused by mental illness. It is therefore, important to have an idea of the 
concepts of mental health and mental illness so that the role and responsibilities of the psychiatrists are made clearer.

Although research is progressing rapidly even now there are few specific biological markers in psychiatry that help diagnose psychiatric illnesses. The burden on the society as a result of neuropsychiatric conditions (a term used to include psychiatric conditions) is massive but stigmatising attitudes towards mental illness, mentally ill people and psychiatrists make it relatively difficult to obtain funding and treatments in many settings. This stigma towards the mentally ill and mental illness discourages those in need from seeking help. Psychiatrists may experience stigma from other mental health professionals and medical colleagues contributing to a sense of rejection and isolation. Thus, a key challenge for society is to deal with and reduce this stigma. Interestingly recent work in the UK has shown some improvement in attitudes or reported behaviour 
but not knowledge indicating that there may be different strands to stigma (6).

Historically, private 'madhouses' and 'public mental asylums' that looked after people with mental illness were often large austere institutions located beyond the limits of the cities and towns that they served. Though often set up with good intentions (and at times manifesting good standards of care) they were amongst the first to suffer in economic crises in terms of resources (and therefore standards of practice) and came to suffer terrible reputations and become further stigmatised. Although psychiatry should take responsibility for ill conceived and sometimes harmful practices used in teh past(just as in medicine and surgery), it is alos important to acknowledge the huge strides that have been made by modern psychiatry towards delivering humane, evidence based and costeffective treatments. Recognition of the damaging effects of social exclusion, stigma and institutionalisation on people with mental illness and learning disabilities has led to policies of deinstitutionalisation and development of community care across 
Europe in recent years. The laudable and welcome aim of deinstitutionalisation is empowerment of patients and their recovery. However, this has been implemented with variable enthusiasm, commitment and success across Europe thereby sometimes resulting in new exclusion and stigma. The old realities of social and psychiatric authoritarianism, coercion and abuse have at times been replaced by the all too frequent new reality of rejection and neglect. Mentally ill and learning disabled people are now to be found increasingly on the streets or in prisons, with all that this entails. In many countries prisons now often act as de facto large institutions. A study from six European countries found that forensic beds had increased in all six countries and the number of general psychiatric beds had gone down in 5 countries and in only two did this reduction outweigh the number of forensic beds thereby indicating an increase in containment (23). Such realities are a constant reminder that the practice of psychiatry requires clear moral and ethical frameworks based on human rights parity. Psychiatrists must have total commitment to the individual patient 
and his/her personal welfare. The patient is at the heart of the therapeutic interactions but he or she is surrounded by kinship, family and society at large. Thus it is critical that there is a clear steer and contract with the society which because of its implicit nature deserves to be reviewed and negotiated regularly.

\section{Mental Disorders and their Treatment}

Treatment requires commitment to working collaboratively with the mentally ill and their families as well as other mental health professionals. Psychiatrists need to be clear about their responsibilities irrespective of resources. Psychiatrists as leaders need not only to engage with the public but also educate them. At the same time psychiatrists have a key responsibility in providing clinical leadership in the development, quality assurance, efficiency and protection of mental health services which must be available to all citizens according to need.

The challenges for psychiatry in the $21^{\text {st }}$ century include a need to encourage the promotion of mental health and prevention of mental 
illness as part of its core practice. Similarly, research and teaching need to become actively engaged in introducing these notions into the public health efforts. As illustrated very briefly above, there is a lot of debate about the concepts of mental disorder and mental illness. Eisenberg (5) argues that the children inherit not only their genes but also parents and their societies as well. He notes that the human brain is influenced by both biological and social factors and that nature and nurture stand in reciprocity. Eisenberg's point (5) that psychiatry is both biological and social often gets forgotten as both sides of the argument may take on very reductionist views. Social inequalities and interpersonal stress affect both mental and physical functioning and influence not only the presentations of psychiatric disorders but also to whom they are presented.

Development of the guidance document: 
This guidance document was developed with reference to the current literature based on documents issued by relevant educational bodies and publications listed on medical databases (PubMed, Medline). The search strategy used the words: role, psychiatrist, mental illness and mental health as key terms. Additional grey literature was searched by hand using existing publications and secondary references. We checked web sites of some psychiatric organisations especially focusing on English speaking countries to collect relevant information.

We made reference to the well-established CanMEDS Physician Competency Framework adopted in 1996 by the Royal College of Physicians and Surgeons in Canada (7); the Royal College of Psychiatrists' occasional paper 74 (22) and the UEMS Charter on Training of medical specialists in the EU: requirements for the specialty of psychiatry $(26,27)$. The models described in these documents are well known models in the articulation of what it means to be a psychiatrist. 


\section{Role of the Psychiatrist}

The Royal College of Psychiatrists (22) proposed that the key aspects of the role are caring for patients from the perspective of medical education and training; managing complexity, severity and risk; teaching and training; research and innovation; challenging stigma and showing leadership. Although it is not made explicit a major responsibility is about holding hope for the patient and holding anxiety for the patient as well as the team.

The CanMEDS (7) model puts the medical expert at the core along with the roles as communicator, collaborator, manager, advocate, scholar and professional. Although the role of the psychiatrist as an 
enabler and facilitator are mentioned in the section on communication, these are significant aspects of the psychiatrists' functioning.

a. Caring for patients:

Patients need good doctors who make the care of the patient their first concern and who are competent, up-to-date, honest and trustworthy. Thus doctors can and must deliver the best care patients need and deserve (7). Thus like other doctors, the primary duty of care of any psychiatrist is their ability to diagnose and manage and thus provide best and evidence based care for the patients. With medical knowledge as its base, psychological and social factors contribute to understanding of aetiology as well as management. A major responsibility for psychiatrists is to engage with patients and their families while keeping the individual at the core of the therapeutic interaction and alliance. However, they need to take into account details of proximal factors which affect the patient and these include employment, family and peers and, also 
distal contextual factors such as society and culture. One of the major expectations of the psychiatrists is their ability to tolerate high levels of anxiety in situations of considerable uncertainty while holding the team's anxiety in check and holding the hope for the patient so that the patient can continue to work through distress. A key skill of psychiatrists is to be empathic and engage patients in both short and long term. For patients who are receiving treatments at the hands of primary care physicians and/ or other mental health professionals the psychiatrist must act as an advocate and set standards for high quality care. Psychiatrists are uniquely trained and skilled in the application of the full bio-psychosocial model, thus setting them apart from other professions that may utilise less holistic and more limited approach.

b. Managing complexity and severity:

Medical expertise embedded in the psychiatrists' training and practice is the key to diagnosis and management especially in complex cases involving co-morbidity. For example severe mental 
illness with addictions or psychiatric disorders with underlying personality disorders or combination of physical and mental illness all require complex interventions and psychiatrists are best placed to deliver these. This ability to understand and manage complexity of illnesses as well as complex health care systems is an important responsibility that the psychiatrists carry with them.

With information overload and changing patient expectations the ability to sift complex data and evidence and then apply this to the individual needs of the patient is a critical skill. Understanding the evidence and its application to clinical efficacy of medication or combined therapies is important part of a clinician's role. Medication in psychiatric conditions is one of many strategies available to clinicians. Not surprisingly it is the responsibility of the psychiatrist to not only evaluate the patient but also stop inappropriate treatments whether they are medications or psychotherapies. This core expertise is the corner stone of managing complexity in psychiatry. Patients should not be prescribed psychotropic medication unnecessarily but neither should they be 
denied such medication out of ignorance or prejudice. Holding the hope for the patient and managing patients' and their families' anxieties is part of the clinical responsibility.

Various other forms of biological forms of intervention are complementary parts of the treatment arsenal at the disposal of psychiatrists.

c. Assessing and Managing Risk:

Assessing and managing risk are important responsibilities of the psychiatrists and must be agreed upon in the implicit contract between psychiatry and society. Local legal and statutory context will enable the psychiatrist to determine and respond to risk. Managing risk in the context of stigma and discrimination is a special skill that improves therapeutic alliance and is a skill for which psychiatrists are well trained. Fellow human feeling, common sense and the knowledge of the relevant law, require using the least restrictive but appropriate approach in all cases. Wherever possible, treatment 
must be carried out in explicit agreement with and collaboration with the patient. Patient choice is extremely important. Sometimes, however, the patient's illness clouds their judgment so severely that the psychiatrist has to take on the heavy burden of responsibility for effecting compulsory detention and treatment under mental health law in order to protect the patient -and less frequently others- from harm.

Changing trends in the rise of compulsory treatment in many settings reflect societal expectations as well as increase in morbidity and severity of illness.

d. Teaching and training:

Psychiatrists like all doctors have a life- long commitment to reflective learning and also teaching patients, families and other health professionals. A key responsibility is critical appraisal of the evidence, mentoring and ethical research and training. Psychiatrist 
should be able to act as role models, educators and mentors and carry on the education of younger generations.

e. Research and innovation:

Not everyone is interested in or able to carry out research but many can interpret new findings and their application to clinical settings in an appropriate translational manner. Psychiatrists, along with basic scientists and other mental health professionals and even service users and carers have key roles in researching the causes, maintaining factors and appropriate treatments for mental disorder. It is important to research and provide the right balance of efficacious and efficient mental health services. Community mental health services are absolutely necessary to support family and carers in shouldering the burden and where possible effecting improvement. However these must be supplemented by appropriate hospital services where indicated.

Psychiatric services to general hospitals are essential as poor physical health affects mental health. Often mental health problems are the 
main reason for actually being admitted to a general hospital ward. Increasing longevity may lead to further co-morbidity with more patients in general hospitals whose mental health problems affect their physical health and vice versa.

\section{e. Advocate/Facilitator/Enabler:}

Applying ethical principles and dealing with discrimination, prejudice and stigma are important skills that psychiatrists must have. Stigma and discrimination against mental illness, mentally ill individuals and even mental health professionals are a big challenge to overcome. Psychiatrists should advocate for their patients, their families, mental health services and the profession as a whole. They must facilitate the patient journey through what can be a bewildering and complex and health care systems.

\section{f. Clinical Leadership:}

Psychiatrists must be able to provide leadership in planning and delivering services which are accessible and appropriate. Leadership 
skills include not only clinical decision making but also managing teams and their dynamics and taking on ambassadorial roles while being aware of potential changes in policies and resource issues. There is no doubt that multidisciplinary team work can help the patient and brings in multiple aspects of care which help recovery through a range of approaches in settings such as hospital, outpatients and community mental health locations.

\section{Mission}

As is clear from the description above, the doctor's mission is no longer considered to be simply providing good clinical care to the patient in front of them. Other roles such as management and leadership are now considered important aspects of medical professionalism. Health policies are now strongly influenced by often conflicting free market principles such as value for money, competition, privatization, political agendas of choice and universal healthcare coverage thus presenting medicine with new economic and political pressures. To competently and successfully care for 
mentally ill patients, a professional needs to fulfil roles and bear their responsibilities not only towards patients care, but also to in-patient units, other team members, their institutions and the wider academic and scientific community. The importance of psychiatrists participating or influencing administration structures and decisions must not be undervalued. If psychiatrists are not part of the decision making process the vacant space in their absence will be filled by other professions who will then shape the environment and conditions in which psychiatrists and their patients see each other in a way that may not always be beneficial to the patient.

Over the past years several challenges have emerged for the medical and psychiatric professions. Some of these are external, such as repeated policy changes over which the profession may not have any control or input; real or perceived discontent on part of patients and their families; competition from other professions; and public stigma and discrimination. Other internal factors such as decreasing confidence about coherent theoretical knowledge base; conflicts about diagnosis and classification and about therapeutic 
interventions may also contribute to challenges to clinical practice (11). Psychiatric trainees also identified similar issues (19). The role of the psychiatrist has also been described by the UEMS $(26,27,28)$ in their Charter on Training of Medical Specialists in the European Union (requirements for the specialty of psychiatry).

\section{Psychiatric competencies:}

As noted above, one of the core competencies in being a good psychiatrist is to do with clear communication. The challenge for psychiatry like the rest of medicine is that with increased specialisation there is a problem that it may be more difficult to have a clear authoritative voice speaking for the whole profession. As part of the clinical competencies full awareness of the role psychotherapies of different kinds play in the therapeutic armamentarium is a must. This experience gives the clinician an opportunity to become aware of their own counter-transference and transference as well as their own prejudices so that they are able to deal with them and learn from them. 


\section{Attaining competencies}

As most young psychiatrists acquire the competencies requisite of a mental health professional through undergraduate (medical school) and postgraduate (residency programmes) training, these formative stages are crucial for the development of competent mental health care professionals. Traditionally, the core of postgraduate psychiatric training has consisted of a combination of clinical rotations in a variety of psychiatric specialties and services. This has included experience of treating patients in a wide range of settings including inpatients, outpatients, community and emergencies. However, there remains a huge variation in training between countries and sometimes even within countries. Standards may be set by local, national and international professional bodies in many European countries but the reality is that often resources influence levels and standards of training and the environment within which such training takes place. Postgraduate psychiatry training schemes in the majority of European countries are developed and evaluated by national education policy makers. During recent decades, there has been an 
emphasis on harmonisation in medical training across Europe driven by the 1993 European Union Council Directive 93/16/EEC (26).

The European Union of Medical Specialties (Union Europeene des Medicins Specialistes; UEMS) and its Section of Psychiatry were established to facilitate this process. In 2003 , the UEMS made a number of recommendations for the effective implementation of training programmes in psychiatry. Recommendations were made for the structure of training programmes, competency-based training standards, standards for training institutions, trainers and supervisors, and quality assurance mechanisms (28). However, despite these directives, recent publications still demonstrate significant differences in content and quality of training curricula across Europe $(14,20,27)$.

Moreover, even with the promotion of these standards, certain important aspects of 'real life' psychiatry are sometimes ignored in many educational and training programmes. This discrepancy has 
occasionally left trainees and young psychiatrists somewhere in the middle between traditional and contemporary psychiatrists, underprepared to meet the needs of modern health services and society at large. With these dilemmas in mind, the definition of core competencies that a $21^{\text {st }}$ century psychiatrist needs to acquire and secondly, who defines these competencies and who will provide this training to young professionals are of utmost importance.

Thus, the definition of the role of psychiatrists carries with itself the need for corresponding alignment of the education system.

Psychiatry remains the most intellectually stimulating, challenging and gratifying medical speciality. At the present time, the speciality stands on the cusp of major discoveries which will lead to exciting discoveries about both mental illness and mental well-being. Development and delivery of newer therapies and the use of social media and investigations will also contribute to continuing improvement in mental health care delivery. 


\section{The Way Forward:}

It is important to understand that the core underlying role of the psychiatrist will be the same no matter where they practise but their responsibilities will change accordingly. Different aspects of a psychiatrist's roles will vary according to the health care systems in which they work and how well resourced these are. Thus in countries where there is a shortage of psychologists and social workers, psychiatrists may end up taking more of these responsibilities or vice versa. However core competencies will remain the same and all training programmes must strive to train in these competencies. In a recent report from the UK on the future of mental health services recommends that integration between primary and secondary care as well as between medical and psychiatric care provide the optimal context (2). This may already exist in many countries in Europe as many primary care physicians may well be dealing with mental health problems in the same way many psychiatrists will be looking 
after physical illnesses. It is imperative that the core aspects of the roles and responsibilities across countries are similar so that competency based training can be delivered. Within Europe there is a need to agree on basic principles as highlighted by the UEMS and outlined in this document so that appropriate training can follow. It is important that depending upon local conditions for clinical practice and training suitable adjustments are made. However, the core competencies and roles should ensure that patients get the best possible psychiatric input they need and deserve.

\section{Recommendations:}

The following recommendations are based on the Royal College of psychiatrists and the UEMS section of psychiatry recommendations supplemented by evidence from grey literature:

Roles and responsibilities

1. Psychiatrists must be professionals with a distinct body of knowledge, skills and attitudes dedicated to better health care. 
2. Psychiatrists must be capable of diagnosing and managing psychiatric disorders in a multiplicity of settings, working with teams and being advocates for their patients and families.

3. Psychiatrists should take the lead in service planning, development and delivery and as part of this responsibility they should work with stakeholders including policy makers to ensure that proper resources are made available

4. Psychiatrists should be technically competent in their field and be up-to-date in their knowledge and be able to follow research developments

5. Psychiatrists must have good listening skills, empathy and high levels of probity and integrity

6. Psychiatrists must be good communicators not only with the patients, their families and stakeholders and also be able to lead on public education and have good advocacy skills

7. Psychiatrists should have high levels of managerial skills in managing resources and teams 
8. Psychiatrists must engage in reflective practice and actively pursue life-long learning.

\section{Training}

1. Full training opportunities in a wide range of psychiatric specialities should be made available

2. Psychiatry training must include opportunities for developing psychopharmacological, psychotherapy and social interventional skills

3. Training must be in multi-disciplinary settings

4. Regular assessment and evaluation of skills must be carried out as part of the training. 


\section{References}

1. Bhugra D: Psychiatry in ancient Indian texts: a review. History of Psychiatry 1992, 3 (10): 167-186.

2. Bhugra D, Carlile A: Starting Today -the future of mental health services. London: Mental Health Foundation 2013

3. Bhugra D, Till A and Sartorius N: What is mental health? International Journal of Social Psychiatry, 2013, 59,3-4

4. Caraka Samhita: Caraka Samhita, Vols I-VI, Jamnagar, India: Shree Gulab Kunverba Ayurvedic Society, 1949.

5. Eisenberg L: The social construction of the human brain. Am J Psych, 1995,152,1563-1575 
6. Evans-Lacko S, Henderson C, Thornicroft G: Public knowledge, attitudes and behaviour regarding people with mental illness in England 2009-2012 Br J Psychiatry 2013 Supp 55, s51-s57

7. Frank JR, Jabbour M et al (eds): Report of the CanMEDS Phase IV, Ottawa: RCPSC 2005

8. GMC: Good Medical Practice. London: GMC 2013

9. HEA: Mental Health Promotion: A Quality Framework. London: HEA 1997.

10. Höschl C., Libiger J. Rights and responsibilities of the psychiatric profession. Acta Psychiatrica Scandinavica 101, 2000, Suppl. 399:40-41.

11. Hunter R, Maclpine I: Three Hundred Years of Psychiatry NY: Carlisle Press 1982

12. Katschnig H. Are psychiatrists an endangered species? Observations on internal and external challenges to the profession. World Psychiatry 2010;9:21-8. 
13. Kristal L: ABC of Psychology. London: Michael Joseph 1981

14. Leucht S, Hierl S, Kissling W, Dold M, Davis JM.

Putting the efficacy of psychiatric and general medicine medication into perspective: Review of metaanalyses.

British Journal of Psychiatry 2012;200(2):97-106.

15. Kuzman MR, Giacco D, Simmons $M$, Wuyts $P$, Bausch-Becker N, Favre G, Nawka A. Psychiatry Training in Europe:view from the trenches Med Teach.

2012;34(10):e708-17.

16. Lotz-Rambaldi W, Schafer I, ten Doesschate R, Hohagen F. Specialist training in psychiatry in Europe Results of the UEMS-survey. European Psychiatry 2008; 23: 157-168.

17. Maslow A: Towards a Psychology of Being. NY: Van Nostrand. 1968

18. MHF: What Works for You? London: MHF. 2008 
19. Nawka A, Rojnic Kuzman M, Giacco D. Trainees'

views on the future of psychiatry: a plethora of

challenges ahead of us. World Psychiatry. 2012

Oct;11(3):203.

20. Oakley C, Malik A. Psychiatric training in Europe. The Psychiatrist 2010; 34: 447-450

21. Priebe S, Badescony A, Friotti A, Hansson L, KilianR, Torres-Gonzales F, et al : Reinstitutionalisation in mental health care: comparison of data on service provision from six European countries. BMJ, 2005,330,123-126

22. RCPsych: Role of the consultant psychiatrist.

Occasional Paper 74. London: RCPsych 2010

23. Sartorius N. : Fighting for Mental Health, Cambridge University Press, Cambridge 2002

24. Szasz T: Myth of mental illness. American Psychologist, 1960, 16, 113-118

25. Thirunavukurasu $\mathrm{M}, \mathrm{P}$ Thirunavakarasu, Bhugra D:

Concepts of mental health: definitions and challenges. 
International Journal of Social Psychiatry, 2013, 59,197-

198

26. UEMS Section for Psychiatry. Charter on training of medical specialists in the EU: requirements for the specialty of psychiatry. Eur Arch Psychiatry Clin Neurosci 1997; 247 Suppl 6: S45-7. http://eurlex.europa.eu/LexUriServ/LexUriServ.do?uri=CONSLEG :1993L0016:20070101:EN:PDFvisited at 04.11.2013

27. UEMS section for psychiatry - participants of the 4th meeting of leaders of European psychiatry, Consensus statement - Psychiatric services focused on a community: challenges for the training of future psychiatrists; Geneva; 2004

28. UEMS Section for Psychiatry - European Board of psychiatry. The profile of a psychiatrist, 2005 http://uemspsychiatry.org/wpcontent/uploads/2013/09/Chapter6-11.10.03.pdf visited at 04.11 .2013 
